\title{
Consumption of processed food dietary patterns in four African populations
}

Michelle D Holmes ${ }^{1,2, *}$, Shona Dalal ${ }^{1}$, Vikash Sewram ${ }^{3}$, Megan B Diamond ${ }^{1}$, Sally N Adebamowo ${ }^{4,5}$, Ikeoluwapo O Ajayi ${ }^{6}$, Clement Adebamowo ${ }^{7,8}$, Faraja S Chiwanga ${ }^{9}$, Marina Nielekela ${ }^{10}$, Carien Laurence ${ }^{11}$, Jimmy Volmink ${ }^{11,12}$, Francis Bajunirwe ${ }^{13}$, Joan Nankya-Mutyoba ${ }^{14}$, David Guwatudde ${ }^{14}$, Todd G Reid ${ }^{15}$, Walter C Willett ${ }^{1}, 2,5$, Hans-Olov Adami ${ }^{1,16}$ and Teresa T Fung ${ }^{5,17}$

'Department of Epidemiology, Harvard T.H. Chan School of Public Health, Boston, MA, USA: ${ }^{2}$ Channing Division of Network Medicine, Brigham \& Women's Hospital, Harvard Medical School, 181 Longwood Avenue, Boston, MA 021 15, USA: ${ }^{3}$ African Cancer Institute, Faculty of Medicine and Health Sciences, Stellenbosch University, Cape Town, South Africa: ${ }^{4}$ Center for Research on Genomics and Global Health, National Institutes of Health, Bethesda, MD, USA: ${ }^{5}$ Department of Nutrition, Harvard T.H. Chan School of Public Health, Boston, MA, USA: ${ }^{6}$ Department of Epidemiology and Medical Statistics, Faculty of Public Health, College of Medicine, University of Ibadan, Ibadan, Nigeria: ${ }^{7}$ Institute of Human Virology, Abuja, Nigeria: ${ }^{8}$ Greenebaum Cancer Center and Institute of Human Virology, University of Maryland School of Medicine, Baltimore, MD, USA: ${ }^{9}$ Department of Internal Medicine, Muhimbili National Hospital, Dar es Salaam, Tanzania: ${ }^{10}$ Department of Physiology, Muhimbili University of Health and Allied Sciences, Dar es Salaam, Tanzania: ${ }^{11}$ Centre for Evidence-Based Health Care, Faculty of Medicine and Health Sciences, Stellenbosch University, Cape Town, South Africa: ${ }^{12}$ The South African Cochrane Centre, South African Medical Research Council, Cape Town, South Africa: ${ }^{13}$ Department of Community Health, Mbarara University of Science and Technology, Mbarara, Uganda: ${ }^{14}$ Department of Epidemiology \& Biostatistics, Makerere School of Public Health, Kampala, Uganda: ${ }^{15}$ Center for Assessment Technology and Continuous Health, Massachusetts General Hospital, Boston, MA, USA: ${ }^{16}$ Department of Medical Epidemiology and Biostatistics, Karolinska Institutet, Stockholm, Sweden: ${ }^{17}$ Department of Nutrition, Simmons College, Boston, MA, USA

Submitted 1 March 2017: Final revision received 6 November 2017: Accepted 27 November 2017: First published online 1 February 2018

\begin{abstract}
Objective: To identify predominant dietary patterns in four African populations and examine their association with obesity.

Design: Cross-sectional study.

Setting/Subjects: We used data from the Africa/Harvard School of Public Health Partnership for Cohort Research and Training (PaCT) pilot study established to investigate the feasibility of a multi-country longitudinal study of noncommunicable chronic disease in sub-Saharan Africa. We applied principal component analysis to dietary intake data collected from an FFQ developed for PaCT to ascertain dietary patterns in Tanzania, South Africa, and peri-urban and rural Uganda. The sample consisted of 444 women and 294 men.

Results: We identified two dietary patterns: the Mixed Diet pattern characterized by high intakes of unprocessed foods such as vegetables and fresh fish, but also cold cuts and refined grains; and the Processed Diet pattern characterized by high intakes of salad dressing, cold cuts and sweets. Women in the highest tertile of the Processed Diet pattern score were 3.00 times more likely to be overweight $(95 \%$ CI $1.66,5.45$; prevalence $=74 \%)$ and 4.24 times more likely to be obese (95\% CI 2.23, 8.05; prevalence $=44 \%)$ than women in this pattern's lowest tertile (both $P<0.0001$; prevalence $=47$ and $14 \%$, respectively). We found similarly strong associations in men. There was no association between the Mixed Diet pattern and overweight or obesity.

Conclusions: We identified two major dietary patterns in several African populations, a Mixed Diet pattern and a Processed Diet pattern. The Processed Diet pattern was associated with obesity.
\end{abstract}

Keywords Dietary patterns Sub-Saharan Africa Processed foods Overweight and obesity 
Traditionally, nutritional concerns in sub-Saharan Africa (SSA) have centred on hunger and underweight. However, economic development and urbanization have shifted traditional physical activity and food patterns. The growing prevalence of overweight and obesity presages an oncoming epidemic of metabolic and cardiovascular disease $^{(1,2)}$.

A population's predominant dietary patterns can be identified empirically using principal component analysis $(\mathrm{PCA})^{(3)}$, which utilizes correlations between food groups and has been used in many populations ${ }^{(4-8)}$. Different dietary patterns have sometimes been found for men and women, and dietary patterns are thus usually derived separately by sex ${ }^{(2,3)}$. Dietary patterns identified by PCA have sometimes been associated with health conditions; these have included $\mathrm{CVD}^{(9)}$, cancer ${ }^{(10)}$, and obesity and overweight $^{(11-13)}$.

There are limited reports describing PCA-derived dietary patterns in SSA. Patterns identified have included those in Eastern Cape Province, South Africa $^{(5)}$; in Burkina Faso $^{(14)}$; in urban Ghana $^{(15)}$; in rural Tanzania ${ }^{(16)}$; in Botswana $^{(17)}$; in Cape Province, South Africa ${ }^{(18)}$; in the Cameroonian military ${ }^{(19)}$; in northern Tanzania ${ }^{(20)}$; and in rural South African adolescents ${ }^{(21)}$. Dietary patterns have been shown to associate with demographic features in SSA including age ${ }^{(14,15)}$, socio-economic status ${ }^{(15,16)}$, family structure $^{(17)}$ and urban/rural residence ${ }^{(17,18)}$. In addition, dietary patterns were associated with chronic diseases such as hypertension ${ }^{(19)}$, diabetes ${ }^{(15)}$, breast cancer ${ }^{(20)}$, oesophageal cancer ${ }^{(5)}$ and skin atopy ${ }^{(18)}$. Four reports have linked PCA-derived dietary patterns with overweight, obesity or BMI among individual SSA countries ${ }^{(14-16,21)}$.

To better understand eating patterns in SSA, we used pilot study data from the Africa/Harvard School of Public Health Partnership for Cohort Research and Training $(\mathrm{PaCT})$ to identify dietary patterns in this population. In addition, we cross-sectionally examined the associations between these patterns and overweight, obesity and BMI.

\section{Methods}

\section{Study population}

The PaCT was originally assembled to test the feasibility of a longitudinal study of non-communicable chronic disease in adults. The study population was recruited in 2011 from five sites in four countries: one site each in Nigeria, Tanzania and South Africa, and two sites in Uganda. Three of the sites were occupational cohorts: we recruited teachers in Tanzania and South Africa, and nurses in Nigeria. The two Ugandan sites were defined geographically; we recruited residents from one rural site and one peri-urban site. We conducted an initial survey of demographics, lifestyle factors and history of chronic illness. We also included a 6-month follow-up survey with a common FFQ. A full description of the study and participants has been given previously ${ }^{(22)}$. English questionnaires were used in Nigeria and South Africa. Questionnaires were translated into local languages, and then backtranslated into English, in Tanzania (where the local language was Kiswahili), in Uganda (where the local languages were Luganda and Runyakitara) and in South Africa (where the local language was Afrikaans). Persons excluded from the current analysis were those with greater than $25 \%$ of FFQ missing data, those without information on BMI or those with a BMI of less than $17 \mathrm{~kg} / \mathrm{m}^{2(23)}$. FFQ information was not available from Nigeria; therefore only four of the five original sites were included in the current analysis (teachers in Tanzania, teachers in South Africa, rural residents in Uganda and peri-urban residents in Uganda).

\section{Development of the PaCT FFQ}

We intended to develop an FFQ harmonized across the four PaCT countries. We began with the validated Harvard Nurses' Health Study $2010 \mathrm{FFQ}^{(24)}$. The Harvard FFQ has been adapted for use in other countries, including Colombia $^{(25)}$, Mexico ${ }^{(26)}$, Canada ${ }^{(27)}$ and Iran ${ }^{(28,29)}$. We thereafter consulted with nutritionists from the PaCT countries on the processes discussed below.

First, we adapted the instructions with additional considerations including food quantification (e.g. household measures), metric system adaptation (e.g. English and metric system), religion (e.g. avoidance of fasting periods) and a lack of familiarity with the concept of averaging. An example of these instructions is as follows: 'How often have you eaten the following foods in the past year? Do not count periods of fasting, such as Ramadan. Please pick only one frequency for each food. A note about serving sizes: 1 cup $=8$ ounces or $250 \mathrm{ml}$. 1 ladle $=1$ large serving spoon $=1 / 2$ cup. If you eat 2 servings of food once a week, then you will check "2-4 per week".'

Second, we included the following food groups in the PaCT FFQ: dairy products; fruits; grains, potatoes and other root vegetables; legumes, vegetables and nuts; meat, fish and eggs; beverages including alcoholic beverages; and other foods. We retained food items on the Harvard FFQ that are also consumed in any of the PaCT countries. Foods on the Harvard FFQ that were not frequently eaten in any PaCT country were omitted (e.g. blueberries). Once food items were determined, we evaluated whether a food is called a different English name in PaCT countries. For example, 'cooked oatmeal/cooked oat bran including instant' on the Harvard FFQ became 'Oats, cooked (porridge)' on the PaCT FFQ. Third, we evaluated the prompts and adapted them for the PaCT FFQ. For example, 'Beans or lentils, dried' on the Harvard FFQ became 'Beans/ legumes (Example mung and soybeans; pigeon, cow, and chickpeas)' on the PaCT FFQ. We also allowed names/ prompts to differ between countries. For example, the additional prompts of 'split peas, lentils, and dried beans' were added for South Africa. 
Finally, we added foods common in each country that do not occur in the Harvard FFQ. These included grains such as millet, sorghum and maize; root vegetables such as cassava and taro; fruits such as jackfruit and guava; vegetables such as okra and pumpkin leaves; meats such as offal/tripe; dried fish; and homemade alcoholic beverages. Country-specific names were used as needed. For example, 'plantains' were referred to as 'gonja or matoke' in Uganda and as 'ndizi' in Tanzania. We also included mixed dishes such as 'maize cooked with beans' and 'pie, pastry with meat filling (meat samosa, vetkoek (in South Africa))'. To be inclusive across all four countries, the final PaCT FFQ contained 175 food items. We also asked type of cooking oil, use of vitamins, meal timing, frequency of meals eaten away from home, frequency of frying food and use of added salt.

\section{Data collection}

Age, sex and site were abstracted from responses to the baseline questionnaire. In Uganda, trained interviewers administered the questionnaire including the FFQ and measured height and weight. In South Africa, nurses visited the schools of teacher participants and measured height and weight, although the questionnaire was selfadministered. Likewise, in Tanzania, teacher participants self-administered the questionnaire; height and weight were recorded at the local district hospital.

\section{Statistical methods}

PCA were conducted separately for men and women and adjusted for age. Analyses were initially stratified by site to account for regional differences and then combined because of the small size of the sample. Descriptive statistics were used to describe the characteristics of the study population and explore the distribution of foods on the FFQ.

Dietary patterns were identified using PCA with orthogonal rotation, which derives non-correlated patterns ${ }^{(3)}$. PCA derives dietary patterns based on correlation between food groups. The number of patterns retained was determined based on visual interpretation of the scree plot of eigenvalues as well as the percentage of total variance explained by each factor. Items with a varimax-rotated factor loading greater than 0.15 were retained in the dietary pattern.

The 175 foods on the FFQ were initially categorized into thirty-seven groups based on similarities in nutrient composition and intake distribution before entry into PCA. The thirty-seven food groups were then further combined to four groups for PCA to compare with the patterns obtained using thirty-seven food groups. Ultimately, thirty-seven groupings were chosen because they explained more variability in the diet and allowed for a more detailed interpretation of dietary patterns. For example, cooked oats, cooked wheat, cooked sorghum, cooked millet meal, cooked finger millet, cooked bulrush millet, cooked mixed grains, dry or cold cereal, roasted or boiled maize, cooked maize meal, creamed sweet corn maize, maize cooked with beans, maize cooked with rice, mixed rice and boiled plain rice were grouped as 'cereals'. 'Starchy roots' included boiled or baked potato, boiled cassava, cassava meal/ flour, cassava in a mixed dish, sweet potato alone, sweet potato in a mixed dish, cocoyam/taro alone, cocoyam/taro in a mixed dish, boiled yam alone, yam fried, yam in a mixed dish and pounded yam.

We separately identified patterns for men and women as they may have different eating patterns, as reported in previous studies ${ }^{(6,7)}$. For each pattern, a factor score was calculated by summing intakes of food groups weighted by their factor loadings and standardized to have a mean of 0 and a standard deviation of 1 . Factor loadings represent correlation coefficients between the food groups and the specific pattern, with positive loadings representing positive correlations and negative loadings representing inverse correlations. Each individual received a score for each pattern indicating how closely similar his/her diet is to the identified dietary pattern. A higher score indicated a person's diet more closely resembled the extracted pattern. Factor scores were divided into tertiles for each food pattern, whereby the first tertile had the lowest consumption and the third tertile the highest consumption.

Multiple logistic regression was used to assess the association between dietary pattern tertiles and overweight and obesity. Low to normal weight was defined as a BMI from 17 to less than $25 \mathrm{~kg} / \mathrm{m}^{2}$. Overweight was defined as a BMI greater than or equal to $25 \mathrm{~kg} / \mathrm{m}^{2}$. Obesity was defined as a BMI greater than or equal to $30 \mathrm{~kg} / \mathrm{m}^{2}$. We used generalized linear regression to assess the association between dietary patterns and continuous BMI. A robust variance structure was used to account for non-normally distributed residuals in BMI. A linear trend test was conducted across continuous values of the dietary patterns.

\section{Results}

Study population characteristics, stratified by sex, are shown in Table 1 . There were more women ( $n$ 444) than men ( $n$ 294). Education greater than high school was prevalent, accounting for $46.4 \%$ of women and $35.4 \%$ of men. Most participants were urban dwellers $(78.6 \%$ of women and $69.7 \%$ of men), with only one rural site. There was a particularly high prevalence of overweight or obesity (59.9\%) and obesity (29.3\%) among women.

Mean daily servings of the thirty-seven food groups, by site and sex, are shown in Table 2. Intakes of food groups differed between men and women within sites, supporting the practice of separate reporting by sex.

We identified two predominant dietary patterns in women (Table 3). The Mixed Diet (factor 1) was characterized by higher intakes of unprocessed foods such as vegetables, fresh fish, cereals, fruits and beans, but also 
Table 1 Characteristics of the study population of women and men from four sites across three sub-Saharan African countries, 2011

\begin{tabular}{lcc}
\hline Characteristic & Women $(n$ 444) & Men $(n$ 294) \\
\hline Age (years) & 38.79 & \\
Mean & 13.0 & 38.63 \\
SD & 22.5 & 13.4 \\
Employment (\%) & 43.0 & 23.8 \\
$\quad$ Self-employed & 34.0 & 22.8 \\
Teacher & 46.4 & $52 \cdot 7$ \\
Other & 4.7 & 35.4 \\
High education* (\%) & & 14.6 \\
Current smoker (\%) & 35.6 & \\
Site (\%) & 21.4 & 46.9 \\
Peri-urban Uganda & 23.9 & 30.3 \\
Rural Uganda & 19.1 & 17.7 \\
South Africa & 78.6 & 5.1 \\
$\quad$ Tanzania & 59.9 & 69.7 \\
Urban (\%) & 29.3 & 31.6 \\
Overweight† (\%) & 8.5 \\
Obeseł (\%) &
\end{tabular}

*Defined as greater than a high school education.

†Defined as $\mathrm{BMI} \geq 25 \mathrm{~kg} / \mathrm{m}^{2}$.

†Defined as $B M I \geq 30 \mathrm{~kg} / \mathrm{m}^{2}$.

processed foods such as cold cuts, salad dressing and canned fish. The Processed Diet (factor 2) was characterized by higher intakes of salad dressing, margarine, chips, coffee, canned fish, spread, sweets and refined grains. The Mixed Diet explained $8.0 \%$ of the variation and the Processed Diet explained $3.7 \%$ of the variation among women.

We also identified two dietary patterns in men similar to those identified in women (Table 3). The first pattern, Mixed Diet, was characterized by higher intakes of unprocessed foods such as vegetables, beans, nuts, cereals and fruits, but also processed foods such as tea, refined grains, diet soda and fruit juice. The second pattern, Processed Diet, was characterized by higher intakes of cold cuts, sweets, yoghurt, salad dressing, canned fish, chips, soda and margarine. The Mixed Diet explained $6.2 \%$ of the variation and the Processed Diet explained $4.1 \%$ of the variation among men.

Tables 4 and 5 show the age-adjusted association between tertiles of dietary pattern intake and the prevalence of overweight and obesity among women and men, respectively. For women, there was a strong association between higher intake of the Processed Diet pattern and being overweight or obese: after adjusting for age, women in the highest tertile of intake of the Processed Diet pattern had 3.00 times the odds being overweight (95\% CI 1.66, 5.45; prevalence $=74 \%)$ and 4.24 times the odds of being obese (95\% CI 2.23, 8.05; prevalence $=44 \%$ ) than women in the lowest tertile of intake (linear trend $P<0.0001$ for both associations; prevalence $=47$ and $14 \%$, respectively). However, after further adjustment for site, the associations between the Processed Diet pattern and overweight/obesity among women were attenuated and no longer statistically significant. There was no association between the Mixed Diet pattern and overweight or obesity (Table 4).
Likewise, for men, there was a strong association between higher intake of the Processed Diet pattern and being overweight or obese. Men in the highest tertile of intake of the Processed Diet pattern had 2.08 times the odds of being overweight (95\% CI 1.07, 4.02; prevalence $=45 \%)$ and 3.59 times the odds of being obese (95\% CI 1.20, 10.71; prevalence $=20 \%)$ than men in the lowest tertile (linear trend $P<0.001$ for both associations; prevalence $=29$ and $5 \%$ respectively). Like results among women, after further adjustment for site, the associations with the Processed Diet pattern and overweight/obesity among men were attenuated and no longer statistically significant. We did not find significant associations between the Mixed Diet pattern and overweight and obesity among men (Table 5).

We also examined the associations between dietary patterns and BMI (Table 6). After adjusting for age, women in the highest tertile of intake of the Processed Diet pattern had a BMI that was $2.84 \mathrm{~kg} / \mathrm{m}^{2}$ higher (95\% CI 1.54 , $4 \cdot 14 \mathrm{~kg} / \mathrm{m}^{2}$ ) than women in the lowest tertile. Men in the highest tertile of intake of the Processed Diet pattern had a BMI that was $1.70 \mathrm{~kg} / \mathrm{m}^{2}$ higher than men in the lowest tertile $\left(95 \%\right.$ CI $\left.0.44,2.95 \mathrm{~kg} / \mathrm{m}^{2}\right)$; however, it was not statistically significant. These associations are also illustrated in Fig. 1: BMI was associated with higher intake of the Processed Diet pattern, with the $P$ for linear trend $<0.0001$ for both women and men. There was no consistent association between BMI and the Mixed Diet pattern for either sex.

\section{Discussion}

There have been a few studies that have examined the association between dietary patterns and body size in individual SSA countries. Five dietary patterns were derived using $24 \mathrm{~h}$ dietary recall data in 252 rural Tanzanian women. Higher intake of a dietary pattern called the 'Purchase' pattern, characterized by bread, cakes (usually fried in oil), sugar and black tea, was associated with higher BMI in the study by Keding et al. ${ }^{(16)}$. A study of 1072 urban residents of Burkina Faso using an eighty-two-item FFQ by Becquey et $a l^{(14)}$ found higher consumption of a 'Modern' dietary pattern characterized by non-fatty meats and poultry, eggs and fatty/processed meats was associated with a higher prevalence of overweight. Similarly, a dietary pattern characterized by animal products derived from a 214-item FFQ in 388 rural South African adolescents was associated with higher BMI in the study by Pisa et al. ${ }^{(21)}$.

In contrast, in a case-control study of 1221 urban Ghanaians with a fifty-one-item FFQ, the predominant dietary patterns were a 'Traditional' dietary pattern, characterized by green leafy vegetables, beans and aubergine, and a 'Purchase' dietary pattern, characterized by juice, sweets, rice, soft drinks and vegetable oil. Individuals in the highest compared with lowest category of the 
Table 2 Mean daily servings of thirty-seven food groups, by site and sex, in the study population of women and men from four sites across three sub-Saharan African countries, 2011

\begin{tabular}{|c|c|c|c|c|c|c|c|c|}
\hline \multirow[b]{2}{*}{ Food group } & \multicolumn{2}{|c|}{ Peri-Urban Uganda } & \multicolumn{2}{|c|}{ Rural Uganda } & \multicolumn{2}{|c|}{ South Africa } & \multicolumn{2}{|c|}{ Tanzania } \\
\hline & Men & Women & Men & Women & Men & Women & Men & Women \\
\hline Cereals & $2 \cdot 85$ & 2.52 & 1.11 & $2 \cdot 38$ & 1.11 & 1.77 & 1.24 & 0.93 \\
\hline Starchy roots & $2 \cdot 30$ & 1.79 & 0.55 & 3.42 & 0.55 & 0.66 & 0.58 & 1.07 \\
\hline Plantains & 1.88 & 2.91 & 0.00 & 4.09 & 0.00 & 0.00 & 0.34 & 0.42 \\
\hline Refined grains & 1.56 & 1.68 & 1.53 & 0.17 & 1.53 & 1.66 & 0.44 & 0.70 \\
\hline Desserts & 0.66 & 0.72 & 0.54 & 0.28 & 0.54 & 0.78 & 1.29 & 0.63 \\
\hline Fruit & 2.07 & $2 \cdot 21$ & $2 \cdot 17$ & 0.99 & $2 \cdot 17$ & 3.45 & 4.13 & 6.43 \\
\hline Other vegetables & 4.23 & 4.35 & 2.03 & $1 \cdot 15$ & 2.03 & 4.07 & $5 \cdot 22$ & 6.95 \\
\hline Fruit juice & 0.36 & 0.28 & 0.34 & 0.00 & 0.34 & 0.86 & 0.21 & $1 \cdot 11$ \\
\hline Beans & $2 \cdot 33$ & 1.68 & 0.27 & 0.83 & 0.27 & 0.41 & $2 \cdot 13$ & $2 \cdot 46$ \\
\hline Nuts & 0.57 & 0.51 & 0.19 & 0.16 & 0.19 & 0.22 & 0.49 & 0.59 \\
\hline Tomato & $2 \cdot 26$ & $2 \cdot 32$ & 0.53 & 0.82 & 0.53 & 1.01 & 1.99 & 2.55 \\
\hline Root vegetables & 0.35 & 0.40 & 0.36 & 0.02 & 0.36 & 0.79 & 0.81 & 1.63 \\
\hline Red meat & 0.77 & 0.56 & 0.80 & 0.24 & 0.80 & 0.83 & 0.50 & 0.73 \\
\hline Organ meat & 0.13 & $0 \cdot 10$ & 0.04 & 0.01 & 0.04 & 0.08 & $0 \cdot 16$ & 0.21 \\
\hline Poultry & 0.13 & 0.07 & 0.38 & 0.00 & 0.38 & 0.46 & 0.06 & 0.06 \\
\hline Cold cuts & 0.03 & 0.03 & 0.50 & 0.00 & 0.50 & 0.69 & 0.11 & 0.13 \\
\hline Dried fish & $0 \cdot 16$ & 0.17 & 0.02 & 0.33 & 0.02 & 0.02 & 0.07 & 0.15 \\
\hline Canned fish & 0.03 & 0.03 & 0.25 & 0.00 & 0.25 & 0.41 & 0.05 & 0.16 \\
\hline Fresh fish & 0.23 & 0.21 & 0.15 & 0.25 & 0.15 & 0.24 & 0.17 & 0.25 \\
\hline Eggs & 0.45 & 0.43 & 0.26 & 0.04 & 0.26 & 0.32 & 0.09 & 0.14 \\
\hline Full-fat milk & 0.34 & 0.15 & 0.32 & 0.03 & 0.32 & 0.54 & 0.11 & 0.19 \\
\hline Low-fat milk & 0.12 & 0.10 & 0.47 & 0.08 & 0.47 & 0.91 & 0.32 & 0.27 \\
\hline Yoghurt & 0.11 & 0.15 & 0.39 & 0.00 & 0.39 & 0.71 & 0.14 & 0.21 \\
\hline Cheese and other & 0.42 & 0.49 & 0.36 & 0.22 & 0.36 & 0.51 & 0.55 & 0.56 \\
\hline Tea & 2.55 & $2 \cdot 23$ & 1.23 & 0.47 & 1.23 & 1.60 & 1.43 & 1.09 \\
\hline Coffee & 0.89 & 0.34 & $1 \cdot 14$ & 0.01 & $1 \cdot 14$ & $1 \cdot 11$ & 0.17 & 0.14 \\
\hline Soda & 0.36 & 0.24 & 0.43 & 0.03 & 0.43 & 0.53 & 0.47 & 0.42 \\
\hline Diet soda & 0.22 & 0.15 & 0.19 & 0.00 & 0.19 & 0.25 & $0 \cdot 10$ & 0.13 \\
\hline Coconut milk & 0.00 & 0.02 & 0.00 & 0.00 & 0.00 & 0.01 & 0.08 & 0.16 \\
\hline Alcohol & 0.37 & 0.10 & 0.49 & 0.09 & 0.49 & $0 \cdot 10$ & 0.08 & 0.07 \\
\hline Sugar & 1.95 & 2.45 & $2 \cdot 23$ & 0.85 & $2 \cdot 23$ & 1.53 & 0.76 & 0.90 \\
\hline Peanut butter & 0.04 & 0.05 & 0.30 & 0.00 & 0.30 & 0.23 & 0.03 & 0.08 \\
\hline Dressing & 0.02 & 0.02 & 0.26 & 0.00 & 0.26 & 0.38 & 0.01 & 0.04 \\
\hline Sweets & 0.02 & 0.07 & 0.35 & 0.00 & 0.35 & 0.51 & 0.11 & 0.12 \\
\hline Chips & 0.20 & 0.17 & 0.36 & 0.00 & 0.36 & 0.50 & 0.19 & 0.28 \\
\hline Spread & 0.06 & 0.09 & 0.35 & 0.03 & 0.35 & 0.50 & 0.07 & 0.13 \\
\hline Margarine & 0.37 & 0.20 & 0.72 & 0.00 & 0.73 & 0.92 & 0.01 & 0.04 \\
\hline
\end{tabular}

Purchase pattern score were younger, had lower BMI and waist-to-hip ratio, and a lower risk of diabetes. On the other hand, those in the lowest category of the Traditional pattern score were older, had a higher waist-to-hip ratio and higher risk of diabetes in the study by Frank et al. ${ }^{(15)}$.

The Purchase pattern in Tanzania described by Keding, the Modern pattern in Burkina Faso described by Becquey and the South African pattern characterized by animal products described by Pisa, like our Processed Diet pattern, could represent the nutrition transition away from the traditional African plant-based diet towards one characterized by processed foods, sweets and animal products $^{(2)}$. We cannot explain the contradictory results for the Purchase pattern in Ghana ${ }^{(15)}$. Evidence of nutrition transition may be evident through the dietary patterns derived in the present study. We did not find a mostly unprocessed pattern; plant foods are now mixed with processed foods (Mixed Diet) and the second most prominent pattern was a Processed Diet pattern.

There were limitations to the current study. Each of our sites had socio-economic characteristics which did not overlap with the other sites. Only one of the four sites was rural. Two of the four (Tanzania and South Africa) represented a highly educated professional group, teachers. The inclusion of teachers who are predominantly women also led to there being more women than men among participants. Dietary patterns may be associated with socio-economic status and urban/rural residence ${ }^{(15-18)}$.

Dietary patterns differed by sex at each site, therefore we reported results separately for women and men. Study site could be a confounder as adjustment for site led to finding no associations. However, we believe this may have represented over-control; essentially the differences in socioeconomic status and urbanicity between sites explained the differences in diet and body size. However, it is also possible that other factors differing between sites, such as physical activity, could be the true confounders. We examined the pattern scores by site and found them not very different. However, we were unable to separately examine dietary patterns and outcomes by individual site and sex because numbers of participants in each category became too small. We also do not have data on physical activity. 
Table 3 Factors explaining dietary patterns among the study population of women and men from four sites across three sub-Saharan African countries, 2011

\begin{tabular}{|c|c|c|c|c|}
\hline \multirow[b]{3}{*}{ Food group } & \multicolumn{2}{|c|}{ Women } & \multicolumn{2}{|c|}{ Men } \\
\hline & Factor 1 loading & Factor 2 loading & Factor 1 loading & Factor 2 loading \\
\hline & Mixed Diet & Processed Diet & Mixed Diet & Processed Diet \\
\hline Other vegetables & 0.86 & & 0.81 & \\
\hline Fresh fish & 0.69 & & 0.18 & \\
\hline Root vegetables & 0.68 & & 0.45 & \\
\hline Cereals & 0.67 & & 0.50 & \\
\hline Tomato & 0.65 & & 0.71 & \\
\hline Fruit & 0.63 & & 0.47 & 0.20 \\
\hline Beans & 0.62 & -0.23 & 0.61 & \\
\hline Cold cuts & 0.61 & 0.41 & & 0.71 \\
\hline Fruit juice & 0.59 & 0.25 & 0.44 & 0.34 \\
\hline Red meat & 0.55 & 0.36 & 0.36 & 0.42 \\
\hline Eggs & 0.48 & 0.29 & 0.30 & \\
\hline Nuts & 0.47 & & 0.56 & \\
\hline Low-fat milk & 0.46 & 0.43 & & 0.39 \\
\hline Organ meat & 0.34 & & 0.40 & \\
\hline Cheese and other & 0.27 & 0.18 & 0.32 & \\
\hline Coconut milk & 0.25 & & & \\
\hline Salad dressing & 0.35 & 0.68 & & 0.60 \\
\hline Poultry & 0.37 & 0.67 & & 0.59 \\
\hline Margarine & & 0.66 & 0.24 & 0.46 \\
\hline Yoghurt & 0.29 & 0.57 & & 0.62 \\
\hline Chips & & 0.56 & 0.30 & 0.49 \\
\hline Spread & & 0.56 & & 0.44 \\
\hline Coffee & & 0.56 & 0.38 & 0.32 \\
\hline Canned fish & 0.49 & 0.52 & & 0.57 \\
\hline Sweets & & 0.51 & & 0.70 \\
\hline Full-fat milk & & 0.51 & 0.32 & \\
\hline Peanut butter & 0.17 & 0.49 & & 0.42 \\
\hline Refined grains & 0.22 & 0.48 & 0.48 & 0.29 \\
\hline Soda & & 0.39 & 0.42 & 0.47 \\
\hline Diet soda & 0.19 & 0.34 & 0.44 & 0.32 \\
\hline Desserts & & 0.34 & 0.27 & \\
\hline Tea & 0.21 & 0.30 & 0.70 & \\
\hline Sugar & & 0.20 & 0.39 & 0.31 \\
\hline Starchy roots & 0.24 & -0.30 & 0.32 & -0.38 \\
\hline Dried fish & & -0.38 & & -0.44 \\
\hline Plantains & & -0.42 & & -0.40 \\
\hline
\end{tabular}

Table 4 Age-adjusted association between dietary patterns and obesity and overweight among women from four sites across three sub-Saharan African countries, 2011

\begin{tabular}{|c|c|c|c|c|c|c|c|c|c|c|}
\hline \multirow[b]{2}{*}{ Factor } & \multicolumn{5}{|c|}{ Overweight } & \multicolumn{5}{|c|}{ Obesity } \\
\hline & Overweight/ $N$ & $\%$ & OR & $95 \% \mathrm{Cl}$ & Trend test ( $P$ value) & Obese/N & $\%$ & OR & $95 \% \mathrm{Cl}$ & Trend test ( $P$-value $)$ \\
\hline \multicolumn{11}{|l|}{ Mixed Diet } \\
\hline Tertile 1 & $91 / 148$ & 61 & 1.00 & Ref. & 0.95 & $54 / 148$ & 36 & 1.00 & Ref. & 0.19 \\
\hline Tertile 2 & $90 / 149$ & 60 & 0.94 & $0.52,1.67$ & & $30 / 149$ & 20 & 0.39 & $0.22,0.72$ & \\
\hline Tertile 3 & $85 / 147$ & 58 & 0.81 & $0.46,1.44$ & & $46 / 147$ & 31 & 0.74 & $0.42,1.29$ & \\
\hline \multicolumn{11}{|c|}{ Processed Diet } \\
\hline Tertile 1 & $70 / 148$ & 47 & 1.00 & Ref. & $<0.0001$ & $21 / 148$ & 14 & 1.00 & Ref. & $<0.0001$ \\
\hline Tertile 2 & $87 / 149$ & 58 & 1.59 & $0.90,2.80$ & & $45 / 149$ & 30 & $2 \cdot 85$ & $1.45,5.63$ & \\
\hline Tertile 3 & $109 / 147$ & 74 & 3.00 & $1.66,5.45$ & & $64 / 147$ & 44 & $4 \cdot 24$ & $2.23,8.05$ & \\
\hline
\end{tabular}

Ref., referent category.

Although a cross-sectional study such as this cannot prove a causal relationship between processed food intake and obesity in SSA, such a relationship has been vigorously espoused on the global stage. Monteiro et $a l{ }^{(30)}$ looked in detail at the 30-year rapid increase in processed food consumption in Brazil. They concluded that although negative impact on chronic disease could not yet be proven, definitive studies should be done; and in the meantime called upon governments to limit the likely damage now. Stuckler et $a l .{ }^{(31)}$ showed that market penetration of processed foods in middle-income countries now equals that of high-income countries, and that 
Table 5 Age-adjusted association between dietary patterns and obesity and overweight among men from four sites across three sub-Saharan African countries, 2011

\begin{tabular}{|c|c|c|c|c|c|c|c|c|c|c|}
\hline \multirow[b]{2}{*}{ Factor } & \multicolumn{5}{|c|}{ Overweight } & \multicolumn{5}{|c|}{ Obesity } \\
\hline & Overweight/N & $\%$ & OR & $95 \% \mathrm{Cl}$ & Trend test ( $P$ value $)$ & Obese/N & $\%$ & OR & $95 \mathrm{Cl} \%$ & Trend test ( $P$ value) \\
\hline \multicolumn{11}{|l|}{ Mixed Diet } \\
\hline Tertile 1 & $32 / 98$ & 33 & 1.00 & Ref. & 0.0012 & $4 / 98$ & 4 & 1.00 & Ref. & 0.56 \\
\hline Tertile 2 & $41 / 99$ & 41 & 1.48 & $0.77,2.83$ & & $13 / 99$ & 13 & 3.51 & $1.08,11.47$ & \\
\hline Tertile 3 & $20 / 97$ & 21 & 0.52 & $0.26,1.06$ & & $8 / 97$ & 8 & 1.95 & $0.54,7 \cdot 11$ & \\
\hline \multicolumn{11}{|c|}{ Processed Diet } \\
\hline Tertile 1 & $28 / 98$ & 29 & 1.00 & Ref. & & $5 / 98$ & 5 & 1.00 & Ref. & 0.0011 \\
\hline Tertile 2 & $21 / 99$ & 21 & 0.78 & $0.38,1.60$ & 0.0004 & $4 / 99$ & 4 & 0.85 & $0.21,3.36$ & \\
\hline Tertile 3 & $44 / 97$ & 45 & 2.08 & $1.07,4.02$ & & $16 / 97$ & 20 & 3.59 & $1.20,10.71$ & \\
\hline
\end{tabular}

Ref., referent category.

Table 6 Age-adjusted mean difference in BMI units $\left(\mathrm{kg} / \mathrm{m}^{2}\right)$ across dietary patterns among women and men from four sites across three sub-Saharan African countries, 2011

\begin{tabular}{|c|c|c|c|c|c|c|}
\hline \multirow[b]{2}{*}{ Factor } & \multicolumn{3}{|c|}{ Women } & \multicolumn{3}{|c|}{ Men } \\
\hline & Adjusted & $95 \% \mathrm{Cl}$ & $\begin{array}{l}\text { Trend test } \\
\text { ( } P \text { value })\end{array}$ & Adjusted & $95 \% \mathrm{Cl}$ & $\begin{array}{l}\text { Trend test } \\
(P \text { value })\end{array}$ \\
\hline \multicolumn{7}{|l|}{ Mixed Diet } \\
\hline Tertile 1 & - & Ref. & $0 \cdot 17$ & - & Ref. & 0.006 \\
\hline Tertile 2 & -1.43 & $-2.61,-0.24$ & & 0.77 & $-0.43,1.96$ & \\
\hline Tertile 3 & -0.18 & $-1 \cdot 56,1 \cdot 21$ & & -0.70 & $-1.86,0.46$ & \\
\hline \multicolumn{7}{|c|}{ Processed Diet } \\
\hline Tertile 1 & - & Ref. & $<0.0001$ & - & Ref. & $<0.0001$ \\
\hline Tertile 2 & $1 \cdot 12$ & $-0.08,2.32$ & & -0.70 & $-1.85,0.45$ & \\
\hline Tertile 3 & $2 \cdot 84$ & $1.54,4.14$ & & 1.70 & $0.44,2.95$ & \\
\hline
\end{tabular}

Ref., referent category.

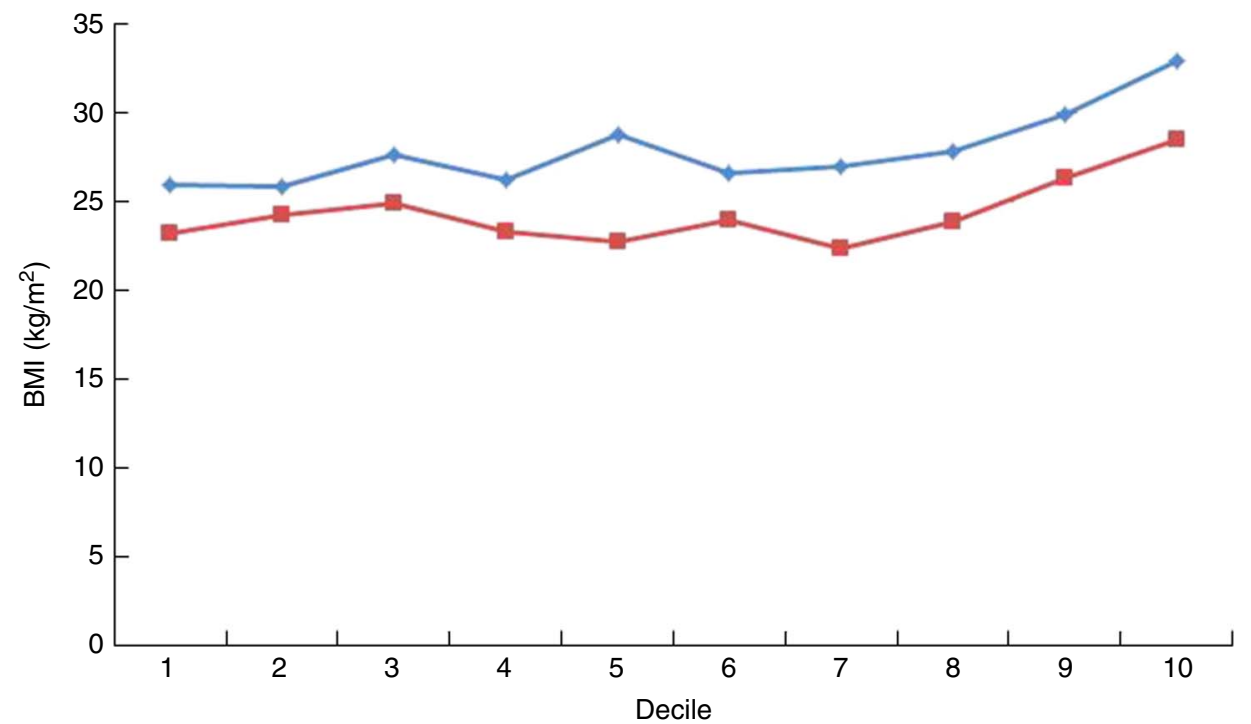

Fig. 1 (colour online) Mean BMI by decile of processed food intake among women $(-\bullet ; n$ 444) and men ( - - ; n 294) from four sites across three sub-Saharan African countries, 2011

the rate of increase of processed food consumption in low- and middle-income countries is even faster than historically seen in high-income countries. If true, this would predict an even more explosive epidemic of obesity and related diseases in SSA countries than the developed world has seen.

The strengths of the present study included the following. We developed a comprehensive, 175-item FFQ 
that allowed for local foods. We were able to assess diet at four sites in three different SSA countries. We demonstrated differences in dietary patterns between women and men. Yet, in both women and men, we demonstrated a Processed Diet pattern that was associated with overweight and obesity.

\section{Conclusion}

In conclusion, we identified a dietary pattern characterized by processed foods that was associated with overweight and obesity in women and men. There is a need in Africa for research that would inform policy makers to make appropriate public health recommendations. Additional studies are needed, particularly longitudinal ones, to examine the extent of modern diet adoption in Africa and to examine its relationship to obesity and other chronic diseases ${ }^{(22,32)}$.

\section{Acknowledgements}

Financial support: This work was supported by a grant from the Dean's Office of the Harvard School of Public Health; the Harvard School of Public Health Department of Nutrition; the Karolinska Institutet Distinguished Professor Award (H.-O.A., award number 2368/10_221); the Faculty of Medicine and Health Sciences at Stellenbosch University; plus The International Society of Nephrology's Global Outreach (ISN GO) Clinical Research and Prevention Program. The funders had no role in the design, analysis or writing of this article. Conflict of interest: None. Authorship: All authors have made substantial contributions to the acquisition and interpretation of the data. In addition, M.D.H., T.T.F., V.S. and M.B.D. contributed to the conception and analysis of the work. All authors have contributed to the drafting or revising of the work for important intellectual content. All authors approved this version for publication. All authors agree to be accountable for all aspects of the work. Etbics of buman subject participation: This study was approved by the Harvard School of Public Health Institutional Review Board; the Institute of Human Virology Heath Research Ethics Committee, Nigeria; the Health Research Ethics Committee of the Faculty of Health Sciences, Stellenbosch University; Makerere University School of Public Health Higher Degrees Research and Ethics Committee; National Institute for Medical Research, Tanzania; Mbarara University of Science and Technology Research Ethics Committee; and the Uganda National Council of Science and Technology.

\section{References}

1. Dalal S, Beunza JJ, Volmink J et al. (2011) Noncommunicable diseases in sub-Saharan Africa: what we know now. Int J Epidemiol 40, 885-901.

2. Steyn NP \& Mchiza ZJ (2014) Obesity and the nutrition transition in sub-Saharan Africa. Ann N Y Acad Sci 1311, 88-101.
3. Gleason PM, Boushey CJ, Harris JE et al. (2015) Publishing nutrition research: a review of multivariate techniques. Part 3: data reduction methods. J Acad Nutr Diet 115 , 1072-1082.

4. DiBello JR, Kraft P, McGarvey ST et al. (2008) Comparison of 3 methods for identifying dietary patterns associated with risk of disease. Am J Epidemiol 168, 1433-1443.

5. Sewram V, Sitas F, O'Connell D et al. (2014) Diet and esophageal cancer risk in the Eastern Cape Province of South Africa. Nutr Cancer 66, 791-799.

6. Ax E, Warensjo Lemming E, Becker W et al. (2016) Dietary patterns in Swedish adults; results from a national dietary survey. Br J Nutr 115, 95-104.

7. Odegaard AO, Koh WP, Yuan JM et al. (2014) Dietary patterns and mortality in a Chinese population. Am J Clin Nutr 100, 877-883.

8. Saadatnia M, Shakeri F, Keshteli AH et al. (2015) Dietary patterns in relation to stroke among Iranians: a case-control study. J Am Coll Nutr 34, 32-41.

9. Rodriguez-Monforte M, Flores-Mateo G \& Sanchez E (2015) Dietary patterns and CVD: a systematic review and meta-analysis of observational studies. Br J Nutr 114, 1341-1359.

10. Brennan SF, Cantwell MM, Cardwell CR et al. (2010) Dietary patterns and breast cancer risk: a systematic review and meta-analysis. Am J Clin Nutr 91, 1294-1302.

11. Arabshahi S, Ibiebele TI, Hughes MC et al. (2017) Dietary patterns and weight change: 15-year longitudinal study in Australian adults. Eur J Nutr 56, 1455-1465.

12. Boggs DA, Palmer JR, Spiegelman D et al. (2011) Dietary patterns and 14-y weight gain in African American women. Am J Clin Nutr 94, 86-94.

13. Shi Z, Yuan B, Hu G et al. (2011) Dietary pattern and weight change in a 5-year follow-up among Chinese adults: results from the Jiangsu Nutrition Study. Br J Nutr 105, 1047-1054.

14. Becquey E, Savy M, Danel P et al. (2010) Dietary patterns of adults living in Ouagadougou and their association with overweight. Nutr J 9, 13.

15. Frank LK, Kroger J, Schulze MB et al. (2014) Dietary patterns in urban Ghana and risk of type 2 diabetes. Br J Nutr 112, 89-98.

16. Keding GB, Msuya JM, Maass BL et al. (2011) Dietary patterns and nutritional health of women: the nutrition transition in rural Tanzania. Food Nutr Bull 32, 218-226.

17. Maruapula S \& Chapman-Novakofski K (2007) Health and dietary patterns of the elderly in Botswana. J Nutr Educ Behav 39, 311-319.

18. Hooper R, Calvert J, Thompson RL et al. (2008) Urban/rural differences in diet and atopy in South Africa. Allergy 63 , 425-431.

19. Nkondjock A \& Bizome E (2010) Dietary patterns associated with hypertension prevalence in the Cameroon defence forces. Eur J Clin Nutr 64, 1014-1021.

20. Jordan I, Hebestreit A, Swai B et al. (2013) Dietary patterns and breast cancer risk among women in northern Tanzania: a case-control study. Eur J Nutr 52, 905-915.

21. Pisa PT, Pedro TM, Kahn K et al. (2015) Nutrient patterns and their association with socio-demographic, lifestyle factors and obesity risk in rural South African adolescents. Nutrients 7, 3464-3482.

22. Dalal S, Holmes MD, Laurence C et al. (2015) Feasibility of a large cohort study in sub-Saharan Africa assessed through a four-country study. Glob Health Action 8, 27422.

23. Odegaard AO, Pereira MA, Koh WP et al. (2008) Coffee, tea, and incident type 2 diabetes: the Singapore Chinese Health Study. Am J Clin Nutr 88, 979-985.

24. Willett W (2012) Nutritional Epidemiology, 3rd ed. New York: Oxford University Press. 
25. Bautista LE, Herran OF \& Pryer JA (2005) Development and simulated validation of a food-frequency questionnaire for the Colombian population. Public Health Nutr 8, 181-188.

26. Hernandez-Avila M, Romieu I, Parra S et al. (1998) Validity and reproducibility of a food frequency questionnaire to assess dietary intake of women living in Mexico City. Salud Publica Mex 40, 133-140.

27. Gao X, Wang Y, Randell E et al. (2016) Higher dietary choline and betaine intakes are associated with better body composition in the adult population of Newfoundland, Canada. PLoS One 11, e0155403.

28. Esmaillzadeh A, Kimiagar M, Mehrabi Y et al. (2007) Dietary patterns and markers of systemic inflammation among Iranian women. J Nutr 137, 992-998.
29. Esmaillzadeh A \& Azadbakht L (2008) Food intake patterns may explain the high prevalence of cardiovascular risk factors among Iranian women. J Nutr 138, 1469-1475.

30. Monteiro CA, Levy RB, Claro RM et al. (2011) Increasing consumption of ultra-processed foods and likely impact on human health: evidence from Brazil. Public Health Nutr 14, $5-13$.

31. Stuckler D, McKee M, Ebrahim S et al. (2012) Manufacturing epidemics: the role of global producers in increased consumption of unhealthy commodities including processed foods, alcohol, and tobacco. PLoS Med 9, e1001235.

32. Holmes MD, Dalal S, Volmink J et al. (2010) Noncommunicable diseases in sub-Saharan Africa: the case for cohort studies. PLoS Med 7, e1000244. 